\title{
Firmeza y compromiso para seguir creciendo
}

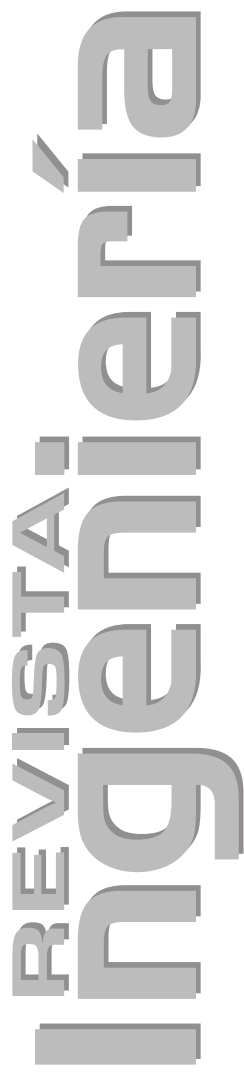

Ha finalizado un nuevo proceso de indexación en Publindex por parte de Colciencias y, en esta ocasión, la Revista Ingeniería ha sido merecedora de ser clasificada en categoría B. Recordemos que en el ejercicio anterior la Revista fue injustamente excluida de dicho índice; no obstante los sólidos reclamos realizados por el equipo editorial que conllevaron a la misma Colciencias a reconocer que a pesar del cumplimiento de los criterios de calidad de la categoría B no reversaría su dictamen oficial por considerarlo un caso particular (como lo ilustramos ampliamente en una nota editorial anterior [1]). Lo anterior afectó notablemente el flujo de envíos de artículos de autores nacionales durante el periodo transcurrido; sin embargo, la firmeza y solidez de los procesos editoriales se han mantenido, permitiendo casi dos años después lograr nuevamente este reconocimiento, que celebramos con la confianza de que revitalice el crecimiento de la Revista en el corto plazo. De allí que aprovecháramos este espacio para compartirlo con nuestra lectores.

Vale la pena observar que la reclasificación se produce de manera simultánea con la actualización de las métricas de impacto calculadas por la base de datos bibliográfica de Google Scholar. En ella, la Revista Ingeniería aparece en las mejores diez revistas hispanoamericanas de esta disciplina [2], obteniendo un índice h5 de 9. Dichas noticias refrescan y reflejan visiblemente el reconocimiento que la comunidad académica hace en relación con la dinámica que ha adquirido los procesos de publicación en la Revista, a la rigurosidad editorial, a la agilidad en la evaluación por pares, al acompañamiento a los autores y en general a la calidad del contenido que la misma difunde. Lo anterior es todavía más notorio al comprobar que en estos dos últimos años

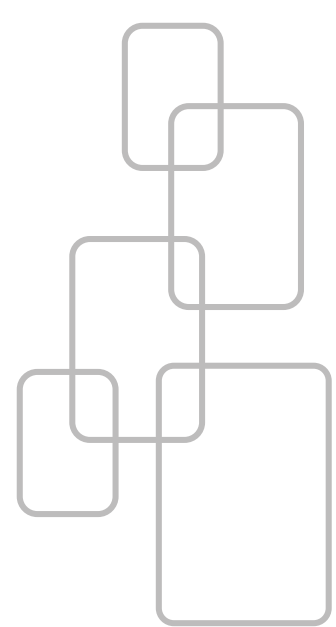
la mayoría de las contribuciones provienen de países como Chile, México, Ecuador, Perú, Cuba y Argentina, demostrando su incursión en la región latinoamericana.

Consideramos que es un momento apropiado para mencionar las iniciativas que esperamos fortalecer en el futuro cercano, buscando continuar avanzando por el sendero del crecimiento y la consolidación como medio de divulgación científica en ingeniería:

- Transición gradual al idioma inglés, mediante el apoyo de correctores de estilo bilingües; esto sin restringir la posibilidad a nuestra comunidad hispanoamericana de lectores y autores de difundir resultados de investigación en su lengua natal. 
- Fortalecimiento la proyección nacional y latinoamericana, a través de alianzas con eventos locales e internacionales para publicar versiones extendidas de mejores trabajos. De esta manera se pretende favorecer la visibilidad de los trabajos más destacados así como de la misma Revista en los grupos de investigación regionales.

- Publicación exclusivamente en línea para evitar retrasos de impresión, además de permitir una reorientación de recursos que agilicen los procesos de gestión editorial.

- Migración a modelo de publicación por secciones especializadas, coordinadas por editores de sección expertos con reconocida trayectoria en sus áreas.

- Seguimiento periódico de desempeño y núcleos de temáticas consolidadas y emergentes, mediante análisis bibliométricos.

- Activación y mantenimiento de redes sociales de la Revista, así como medición de indicadores alternativos de visibilidad (Altmetrics).

- Revisión de inclusión en Emerging Sources Citation Index y, en un mediano plazo, gestionar y posicionar la revista en otros índices bibliográficos citacionales como Web of Science y SCImago.

De esta manera queremos invitar a nuestra comunidad de lectores, autores y evaluadores a acompañarnos en estas iniciativas y participar en este proyecto colaborativo de construcción de un espacio idóneo para la divulgación de sus resultados de investigación, con criterios rigurosos, eficientes y efectivos en términos de amplia visibilidad e impacto. De nuestra parte, ofreceremos nuestro mejor esfuerzo y compromiso para lograrlo.

Bogotá D.C., 1 de septiembre de 2019

Nelson Leonardo Diaz A., PhD. Editor Revista INGENIERÍA

Sergio A. Rojas, PhD. Editor Honorario INGENIERÍA

\section{Referencias}

[1] Rojas, S. A. "Excluidos sin justa causa”. Ingeniería, vol. 23, núm. 1, pp. 4-6, Ene. 2018.个207

[2] Google Scholar, "20 publicaciones principales que coinciden con ingeniería”. [En línea] Disponible en: https://scholar.google.com/citations?hl=es\& view_op=search_venues\&vq=ingenieria\&btnG=(ultimaconsulta: septiembre01de2019) $\uparrow 207$ 